\title{
Desarrollo de la corteza: Estudio comparativo en dos especies de Ceiba (Malvaceae)
}

\section{Bark development: Comparative study of two Ceiba (Malvaceae) species}

\section{Acta Botanica Mexicana}

\author{
Sandra Guía-Ramírez' (1) , Teresa Terrazas² (1) , Silvia Aguilar-Rodríguez ${ }^{1 / 4}$ (D) , \\ Laura Yáñez-Espinosa ${ }^{3}$ (D) , José Daniel Tejero-Díezl (0)
}

\section{Resumen:}

Antecedentes y Objetivos: Ceiba aesculifolia y C. pentandra (Malvaceae) son dos de las cuatro especies de Ceiba presentes en México. Se conocen como "pochotes"; sus cortezas tienen usos ornamentales y medicinales. Con la finalidad de encontrar atributos distintivos entre estas dos especies de amplia distribución en el país, se realizó un estudio comparativo de la estructura anatómica de la corteza a lo largo de sus ejes y su relación con posibles adaptaciones ecológicas.

Métodos: Se recolectaron muestras desde las ramas nuevas hasta el tronco principal de cuatro individuos en un bosque tropical caducifolio de los estados de México y Puebla. Se realizaron cortes histológicos de la corteza con un microtomo de deslizamiento; las secciones se tiñeron con safranina-verde rápido y se montaron en resina sintética.

Resultados clave: La corteza es ligeramente fisurada a fisurada en tallos maduros, de color gris plomizo en C. aesculifolia y verde en C. pentandra; con aguijones. La peridermis se origina de un estrato subepidérmico en los ápices de las ramas; conforme los ejes aumentan en diámetro, los radios se dilatan fuertemente (forma de embudo) y las fibras del floema se organizan en estratos, características compartidas con otras Bombacoideae (Malvaceae). Ceiba pentandra mantiene parches de peridermis que se alternan con epidermis, aguijones no estratificados y drusas escasas $\left(<20 / \mathrm{mm}^{2}\right)$, mientras que en C. aesculifolia hay ritidoma, aguijones estratificados y drusas abundantes $\left(50-60 / \mathrm{mm}^{2}\right)$.

Conclusiones: Detalles de los cambios estructurales a lo largo del eje, además de las diferencias encontradas entre ambas especies, se reportan por primera vez para Ceiba. La rápida diferenciación de la peridermis en las ceibas estudiadas se interpreta como una adaptación para protección de la luz solar y la desecación; aspecto que ha sido observado en otras especies que crecen en ambientes estacionales.

Palabras clave: bosque tropical caducifolio, córtex, ontogenia, peridermis, pochote.

\section{Abstract:}

Background and Aims: Ceiba aesculifolia and C. pentandra (Malvaceae) are two of the four Ceiba species growing in Mexico. They are recognized as "pochotes" and have ornamental and medicinal use of their bark. In order to find distinctive attributes between these species of wide distribution in the country, a comparative study of the anatomical structure of the bark along its axes and the relationship with possible ecological adaptations were carried out.

Methods: Samples from the new branches to the main trunk of four individuals were collected from the deciduous tropical forest of the State of Mexico and Puebla. Histological sections of the bark were cut with sliding microtome; the sections were stained with safranine-fast green and mounted in synthetic resin.

Key results: The bark is slightly fissured to fissured on mature stems, leaden-gray color in C. aesculifolia and green in C. pentandra; with prickles. The peridermis originates from a subepidermal layer at the branch tips; as the axes increase in diameter, the rays strongly dilate (wedge-shaped) and the phloem fibers are organized in strata, characteristics shared with other Bombacoideae (Malvaceae). Ceiba pentandra maintains patches of peridermis that alternate with epidermis, unstratified prickles and few druses $\left(<20 / \mathrm{mm}^{2}\right)$, while in $C$. aesculifolia there is a rhytidome, stratified prickles, and abundant druses $\left(50-60 / \mathrm{mm}^{2}\right)$.

Conclusions: Details of structural changes along the axis, in addition to the differences found between both species are reported for the first time for Ceiba. The rapid differentiation of the peridermis in the ceibas studied is interpreted as an adaptation to protect against sunlight and desiccation; an aspect that has been observed in other species growing in seasonal environments.

Key words: cortex, deciduous tropical forest, ontogeny, peridermis, pochote.

${ }^{1}$ Universidad Nacional Autónoma de México, Facultad de Estudios Superiores Iztacala, Unidad de Morfología y Función, Laboratorio de Botánica, Av. de los Barrios Núm. 1, 54090 Los Reyes Ixtacala, Tlalnepantla, Estado de México, México.

${ }^{2}$ Universidad Nacional Autónoma de México, Instituto de Biología, Ciudad Universitaria, 04510 Cd. Mx., México.

${ }^{3}$ Universidad Autónoma de San Luis Potosí, Instituto de Investigación de Zonas Desérticas, 78377 San Luis Potosí, México.

${ }^{4}$ Autor para la correspondencia: siagro@unam.mx
Recibido: 27 de agosto de 2020.

Revisado: 24 de septiembre de 2020

Aceptado por Rosario Redonda-Martínez: 13 de noviembre de 2020.

Publicado Primero en línea: 25 de noviembre de 2020. Publicado: Acta Botanica Mexicana 128(2021).

c) (i) (8) Este es un artículo de acceso abierto C. ${ }_{\text {EY }}$ bajo la licencia Creative Commons 4.0 Atribución-No Comercial (CC BY-NC 4.0 Internacional).
Citar como: Guía-Ramírez, S., T. Terrazas, S. Aguilar-Rodríguez, L. Yáñez-Espinosa y J. D. Tejero-Díez. Desarrollo de la corteza: Estudio comparativo en dos especies de Ceiba (Malvaceae). 2020. Acta Botanica Mexicana 128(2021): e1781. DOI: https://doi.org/10.21829/ abm128.2021.1781 


\section{Introducción}

La corteza es la capa más externa de los tallos en especies leñosas; comprende, en su acepción más estricta, todos aquellos tejidos que se encuentran por fuera del cambium vascular (Angyalossy et al., 2016). Consiste en un conjunto de tejidos cuya intrincada organización las hace difíciles de interpretar (Trockenbrodt, 1991); sin embargo, el estudio de su anatomía ha aportado información relevante en diversos campos relacionados con la sistemática y la ecología (Metcalfe, 1979; Angyalossy et al., 2016).

Desde principios del siglo XX, en ecosistemas forestales intertropicales, se han usado las características morfológicas de las cortezas para la determinación de especies (Jiménez-Saa, 1967; Roth y Cova, 1969) y dicha práctica ha continuado (den Outer, 1972; Ghouse et al., 1979; Rollet, 1980, 1982; Roth, 1981; Iqbal y Ghouse, 1982; Yunus et al., 1990; Roth y Giménez, 1997; Hawthorne, 2006; PérezJiménez y Barajas-Morales, 2011; Biswas et al., 2016). Aunque los caracteres anatómicos de la corteza también pueden aportar datos significativos para el reconocimiento de especies, estudios en este campo son escasos y los de desarrollo aún más (Trockenbrodt, 1991; Angyalossy et al., 2016), por lo que aún quedan grandes lagunas en el conocimiento de sus diferencias estructurales y ontogenéticas (Hamann et al., 2011).

De los trabajos destacados en la estructura anatómica de cortezas en árboles tropicales, se encuentra el de Roth (1981), quien da a conocer más de 50 familias diferentes, con aproximadamente 260 especies que crecen en Venezuela. En esa obra, de Malvaceae (=Bombacaceae) se describe a Ceiba pentandra (L.) Gaertn. entre otras congenéricas. Para México, Muñoz-Cázares et al. (2018) compararon anatómicamente la corteza del tallo principal de dos especies de Ceiba Mill. Estudios particulares sobre el desarrollo de cortezas son aún más escasos. Orduño-Cruz y Terrazas (1998) y Aguilar-Rodríguez et al. (2019) estudiaron especies mexicanas de la familia Fabaceae de ambientes xerófitos, tratando de correlacionar posibles adaptaciones estructurales de la corteza con el ambiente semiárido. En ese contexto, pero en Malvaceae, se reconoce el trabajo de Kotina et al. (2017), quienes describen la anatomía de Adansonia digitata $\mathrm{L}$.
Ceiba (Malvaceae) es un género representado por 17 especies, con distribución en América (Gibbs y Semir, 2003; Diego-Pérez y Gómez-Campos, 2013); crece principalmente en las zonas cálido húmedas y subhúmedas del Neotrópico. Se diferencia de otros árboles caducifolios de la misma zona ecológica por la presencia de elementos cónicos apiculados en la corteza, a los que se les denomina indistintamente espinas o acúleos (Carranza-González y Blanco García, 2000; Gibbs y Semir, 2003; Pagaza-Calderón y FernándezNava, 2004; Diego-Pérez y Gómez-Campos, 2013). En México se encuentran Ceiba acuminata (S. Watson) Rose, $C$. aesculifolia (Kunth) Britten \& Baker f., C. pentandra y $C$. schottii Britten \& Baker f. (Villaseñor, 2016), de las cuales C. aesculifolia y C. pentandra son de amplia distribución, formando parte de los bosques tropicales de México (Rzedowski, 1978). La corteza de ambas especies se emplea ampliamente en la medicina herbolaria para tratar padecimientos relacionados con los aparatos circulatorio, digestivo y renal, entre otros (Nicolson, 1979; Gibbs y Semir, 2003) y por ello se llegan a comercializar indistintamente.

Diferenciar las cortezas de C. aesculifolia y $C$. pentandra fue uno de los objetivos del estudio de MuñozCázares et al. (2018), quienes destacan sus propiedades fitoquímicas. Sin embargo, como sucede con otros tejidos del tallo, la variación axial es tal, que distinguir especies a partir de muestras herbolarias llega a ser difícil. Debido a que no se conoce la variación de la corteza de Ceiba y el conocimiento de la variabilidad a lo largo del eje es importante si se utiliza con fines taxonómicos, el objetivo del presente trabajo fue realizar un análisis comparativo de la anatomía de la corteza de $C$. aesculifolia y $C$. pentandra a lo largo del eje, con la finalidad de buscar caracteres consistentes que ayuden a separar estas dos especies, así como algunas de sus posibles adaptaciones ecológicas.

\section{Materiales y Métodos}

Las muestras para el estudio de C. aesculifolia y C. pentandra se recolectaron en Tonatico, Estado de México y Xicotepec, Puebla (Cuadro 1). Se seleccionaron dos ejemplares de cada especie, sanos y sin daño aparente en el tronco (Cuadro 2). En el tronco principal, a 1.30 m del suelo, se llevó a cabo la descripción superficial de las cortezas; con base en la termi- 
Cuadro 1: Datos de colecta de Ceiba aesculifolia (Kunth) Britten \& Baker f. y C. pentandra (L.) Gaertn.

\begin{tabular}{|c|c|}
\hline Especie & Ejemplares de respaldo \\
\hline \multirow[t]{2}{*}{ Ceiba aesculifolia (Kunth) Britten \& Baker f. } & $\begin{array}{l}\text { MÉXICO. México, municipio Tonatico, Los Amates (San José de los Amates), } 1552 \text { m, } 18^{\circ} 46^{\prime} 51^{\prime \prime} \mathrm{N} \text {, } \\
99^{\circ} 40^{\prime} 20^{\prime \prime O} \text {, bosque tropical caducifolio, } 13 . \mathrm{VI} .2015 \text {, S. Aguilar } 707 \text { (IZTA). }\end{array}$ \\
\hline & $\begin{array}{l}\text { MÉXICO. México, municipio Tonatico, Los Amates (San José de los Amates), } 1554 \text { m, } 18^{\circ} 46^{\prime} 50^{\prime \prime} \mathrm{N} \text {, } \\
99^{\circ} 40^{\prime} 53^{\prime \prime O} \text {, bosque tropical caducifolio, } 13 . \mathrm{VI} .2015 \text {, S. Aguilar } 708 \text { (IZTA). }\end{array}$ \\
\hline \multirow[t]{2}{*}{ Ceiba pentandra (L.) Gaertn. } & $\begin{array}{l}\text { MÉXICO. Puebla, municipio Xicotepec, Puente el Higüero, río La Ceiba, comunidad Villa Ávila } \\
\text { Camacho (“La Ceiba”), } 309 \text { m, } 20^{\circ} 19^{\prime} 35^{\prime \prime} \mathrm{N}, 97^{\circ} 52^{\prime} 34^{\prime \prime} \text {, bosque tropical subcaducifolio. } \\
\text { 24.X.2014. S. Aguilar } 643 \text { (IZTA). }\end{array}$ \\
\hline & $\begin{array}{l}\text { MÉXICO. Puebla, municipio Xicotepec Puente el Higüero, río La Ceiba, comunidad Villa Ávila } \\
\text { Camacho (“La Ceiba”), } 312 \text { m, 20¹9'35"N, 9752'34"O, bosque tropical subcaducifolio. } \\
\text { 24.X.2014. S. Aguilar } 644 \text { (IZTA). }\end{array}$ \\
\hline
\end{tabular}

Cuadro 2: Ceiba aesculifolia (Kunth) Britten \& Baker f. y C. pentandra (L.) Gaertn.: altura, diámetro y espesor de la corteza.

\begin{tabular}{|c|c|c|c|c|}
\hline Especie & Individuo (No. Col.) & $\begin{array}{l}\text { Altura del individuo } \\
(\mathrm{m})\end{array}$ & Diámetro $(\mathrm{cm})$ & $\begin{array}{l}\text { Espesor de la corteza } \\
\qquad(\mathrm{cm})\end{array}$ \\
\hline \multirow[t]{2}{*}{ Ceiba aesculifolia (Kunth) Britten \& Baker f. } & $1(707)$ & 15 & 92 & 2.5 \\
\hline & $2(708)$ & 3 & 9 & 0.32 \\
\hline Ceiba pentandra (L.) Gaertn. & $1(643)$ & 4 & 15 & 1.1 \\
\hline
\end{tabular}

nología de Pérez-Jiménez y Barajas-Morales (2011). Para el estudio anatómico se obtuvieron las cortezas de ramas de distintos diámetros en sentido basipétalo, de acuerdo con Orduño-Cruz y Terrazas (1998).

Todas las muestras se colocaron por separado en bolsas de plástico, acompañadas con su respectiva etiqueta de identificación; se fijaron en FAA (etanol 96\% 50 ml, ácido acético glacial $5 \mathrm{ml}$, formaldehído $37-40 \% 10 \mathrm{ml}$ y agua destilada $35 \mathrm{ml}$ ), durante dos semanas. Posteriormente, las muestras se almacenaron en glicerina:alcohol:agua (1:2:3), para ablandarlas por un periodo de 30 días, antes de su procesamiento histológico. Se hicieron cortes transversales, radiales y tangenciales seriados de madera a corteza, de 20 a $35 \mu \mathrm{m}$ de grosor con un micrótomo de deslizamiento (marca Leica SM2010 R, Nussloch, Alemania). Algunos cortes de diferentes planos se aclararon con hipoclorito de sodio (Aguilar-Rodríguez, 1998). En todos los casos las secciones se tiñeron con safranina-verde rápido y se montaron en resina sintética (Johansen, 1940). Las mediciones e imágenes, por diámetro de ramas desde el ápice hasta la base del tallo, se obtuvieron empleando el analizador Nikon NISElements BR software para Windows, versión 3.2. (Nikon Corporation, 1991-2006), adaptado a un microscopio óptico (Nikon Eclipse E200, Tokio, Japón). Las descripciones se hicieron con base en la terminología de Angyalossy et al. (2016). El material herborizado se encuentra depositado en el herbario IZTA (acrónimo de acuerdo con Thiers, 2018).

\section{Resultados}

\section{Morfología externa de la corteza del tallo principal}

Ceiba aesculifolia tiene una corteza ornamentada con aguijones apiculados, robustos, cónicos y de textura rugosa (Fig. 1A). Su color es gris plomizo, homogéneo, con grandes bandas verticales amplias y de color amarillento; es extremadamente gruesa (Cuadro 2) con hasta $25 \mathrm{~mm}$ de ancho en corte transversal. En los troncos viejos los aguijones se pueden fusionar formando pliegues o costillas evidentes.

En C. pentandra, la corteza es ornamentada, con aguijones cónicos - de ápice acuminado que pueden llegar 

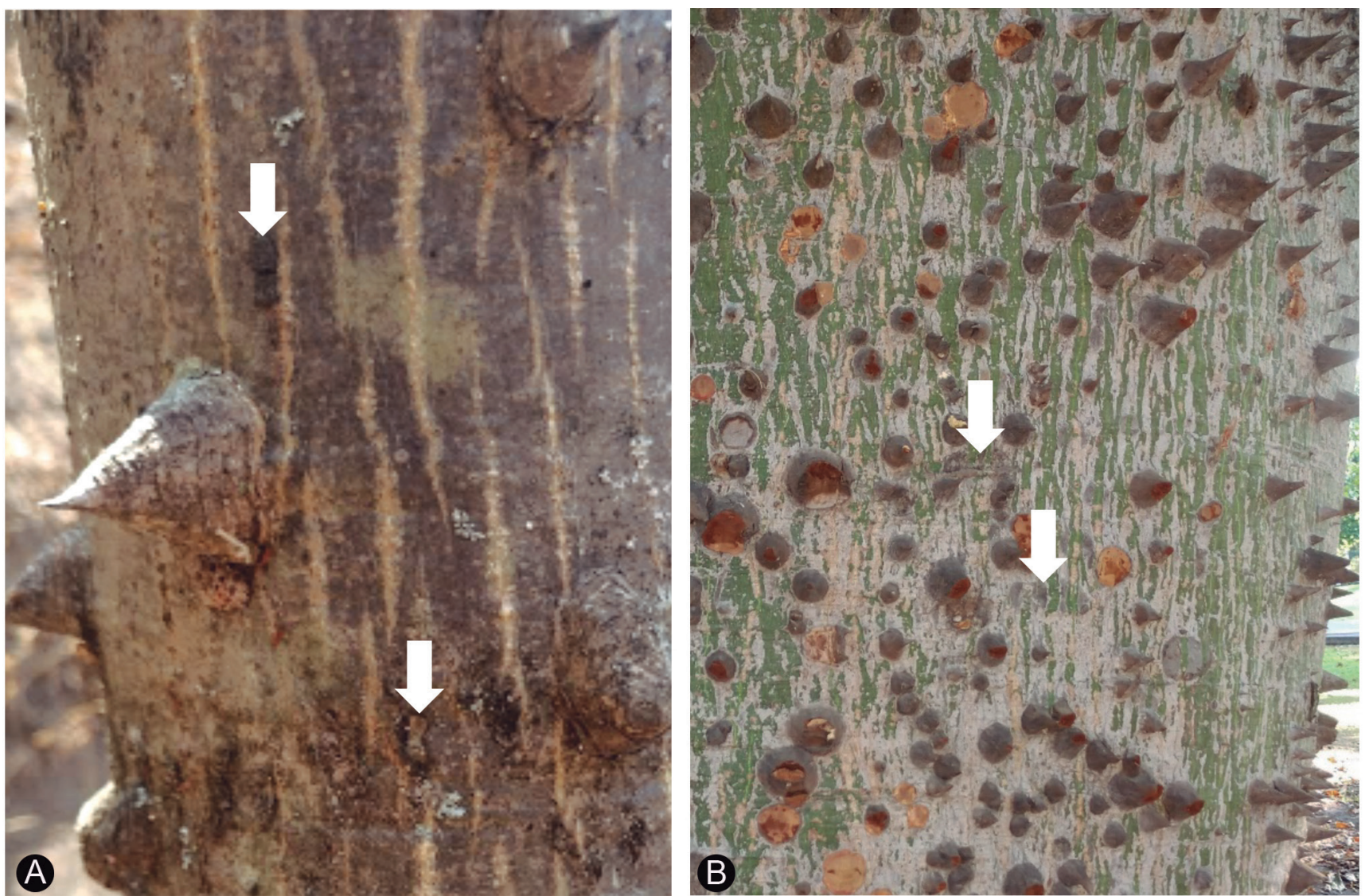

Figura 1: Morfología de la corteza de Ceiba Mill. en individuos de $\geq 80 \mathrm{~cm}$ diámetro. A. Ceiba aesculifolia (Kunth) Britten \& Baker f., aguijones de textura rugosa (fechas=ritidoma); B. Ceiba pentandra (L.) Gaertn., aguijones de textura lisa (flechas=peridermis).

a doblarse ligeramente - y textura lisa. Su color es verdoso, con bandas verticales cortas - a veces no bien definidas y parecidas a pequeñas grietas o cicatrices-, de color amarillo pajoso (Fig. 1B); es gruesa, con hasta $18 \mathrm{~mm}$ de ancho en corte transversal.

\section{Anatomía del desarrollo}

Ramas de $5 \mathrm{~mm}$ de diámetro

En vista transversal, la cutícula es delgada y la epidermis simple, con células de paredes delgadas, cuadrangulares y en ocasiones rectangulares, en C. aesculifolia (Fig. 2A), pero la pared periclinal externa en $C$. pentandra es ligeramente elevada (Fig. 3B). En C. aesculifolia, subyacente a la epidermis, existe una hipodermis de un solo estrato, con algunas células con contenidos obscuros y otras con drusas, por debajo (en el córtex) se organiza la primera peridermis (Figs. $2 \mathrm{~A}, \mathrm{C}$ ). En $C$. pentandra no se observa una hipodermis. En el córtex de ambas especies se reconocen tres regiones en sentido centrípeto (Figs. 2A, B, 3A). La primera región (PR) se constituye de células de parénquima con cloroplastos, algunas con taninos o drusas (C. aesculifolia); en la segunda región (SR) se observa colénquima con algunas células ya lignificadas en $C$. aesculifolia (Figs. 2A, B); mientras que en $C$. pentandra las células corresponden a colénquima angular que contienen drusas escasas (Fig. 3B). En la tercera región (TR) de ambas especies, se encuentran canales de mucílago en una matriz de parénquima cuyas capas más internas presentan abundantes drusas (Figs. 2B, 3A); además, hay taninos que ocluyen el lumen celular de las células de parénquima. El cilindro vascular presenta cuatro haces de tipo colateral; en C. aesculifolia son de forma ligeramente elíptica, entre ellos las células se lignifican formando un anillo continuo con el establecimiento de cambium vascular, y sobre el floema se observa un cilindro casi completo de fibras pericíclicas (Fig. 2B). En C. pentandra los haces pueden tener forma elíptica a redondeada (Fig. 3C), cada uno de ellos está rodeado casi en su totalidad de un cas- 

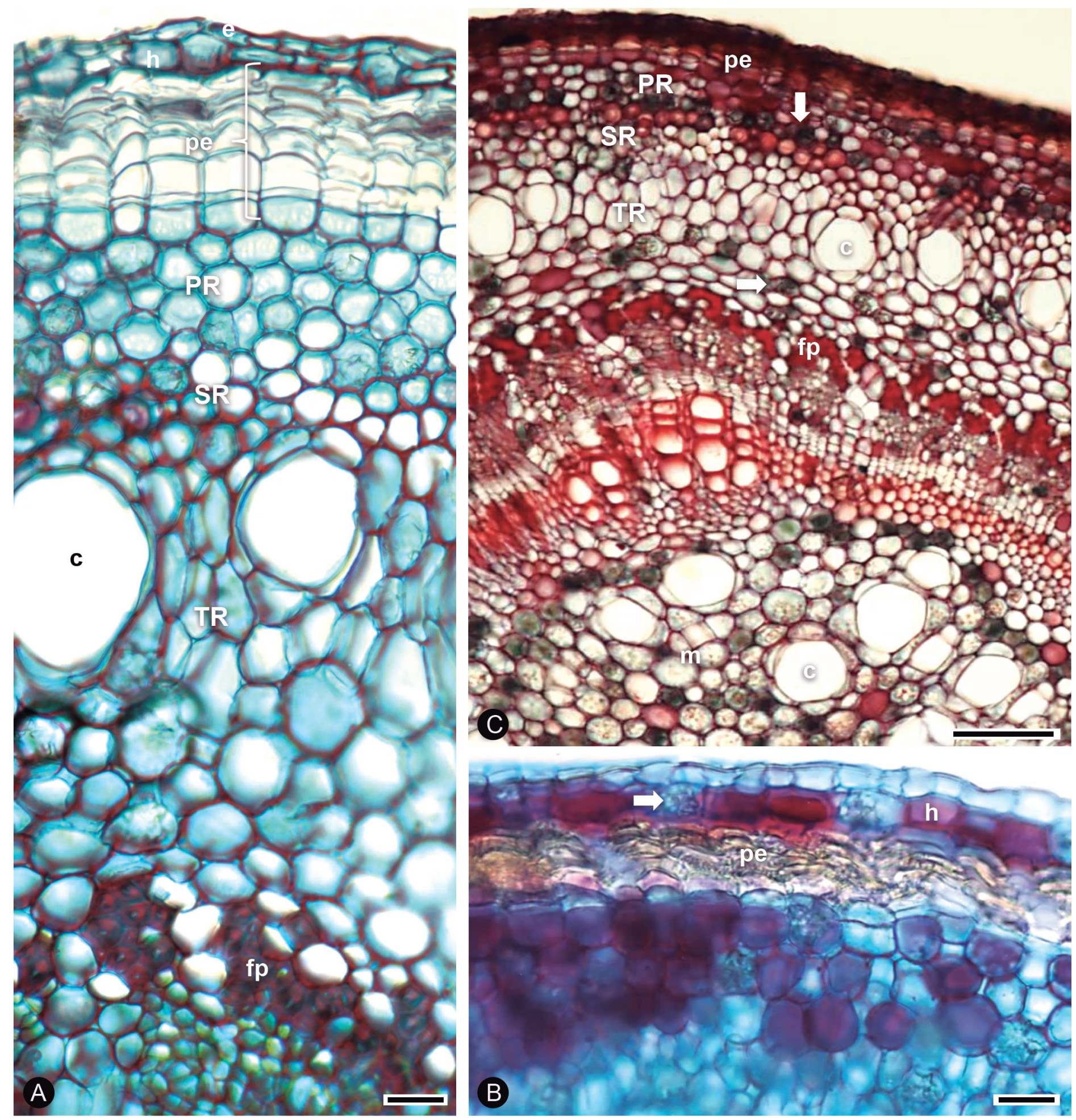

Figura 2: Ramas de $5 \mathrm{~mm}$ de diámetro de Ceiba aesculifolia (Kunth) Britten \& Baker f., CTR. A. epidermis simple y las tres zonas del córtex, células de colénquima en la SR (corte aclarado); B. tres regiones del córtex (corte sin aclarar); C. detalle de hipodermis con células con contenidos o drusas.

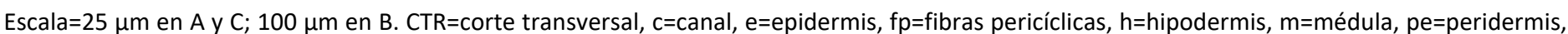
$P R=$ primera región, $S R=$ segunda región, $T R=$ tercera región, flechas=drusas. 

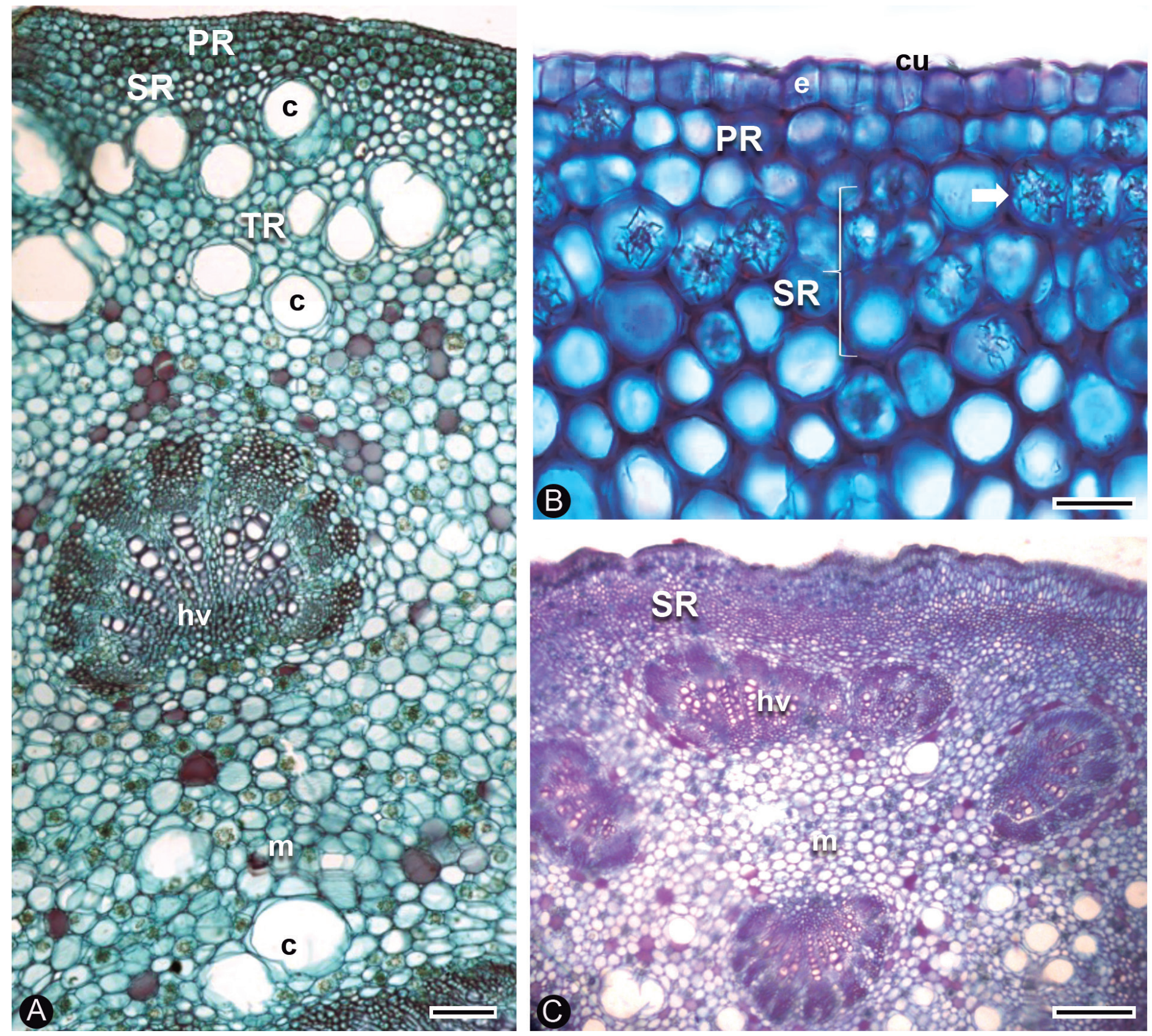

Figura 3: Ramas de $5 \mathrm{~mm}$ de diámetro de Ceiba pentandra (L.) Gaertn., CTR. A. córtex con tres regiones distinguibles; B. detalle de la epidermis simple y primera región formada por células de parénquima y la segunda región por colénquima, ambas con drusas; $C$. distribución del tejido vascular. Escala $=250 \mu \mathrm{m}$ en A, C; $25 \mu \mathrm{m}$ en B. CTR=corte transversal, c=canal, cu=cutícula, e=epidermis, hv=haz vascular, $\mathrm{m}=$ médula, $\mathrm{PR}=$ primera región, $\mathrm{SR}=$ segunda región, $\mathrm{TR}=$ tercera región, flechas=drusas.

quete de fibras pericíclicas que se invaginan hacia la médula (Figs. 3A, C). En el floema conductor (Figs. 4A, B), los elementos de tubo criboso y células acompañantes, (ETcC) se distribuyen en bandas radiales, son solitarios o en grupos de 2-3, se aprecian algunas fibras en hileras tangenciales y abundantes drusas en los radios en $C$. pentandra. En el xilema los vasos se agrupan radialmente. La médula pre- senta células de parénquima con taninos y drusas, además de canales de mucílago (Figs. 2B, 3C).

Ramas de $1 \mathrm{~cm}$ de diámetro

Continúan distinguiéndose las tres regiones del córtex. En C. aesculifolia se forma una peridermis que rodea completamente a la rama (Fig. 5A), la hipodermis ya no se aprecia. 

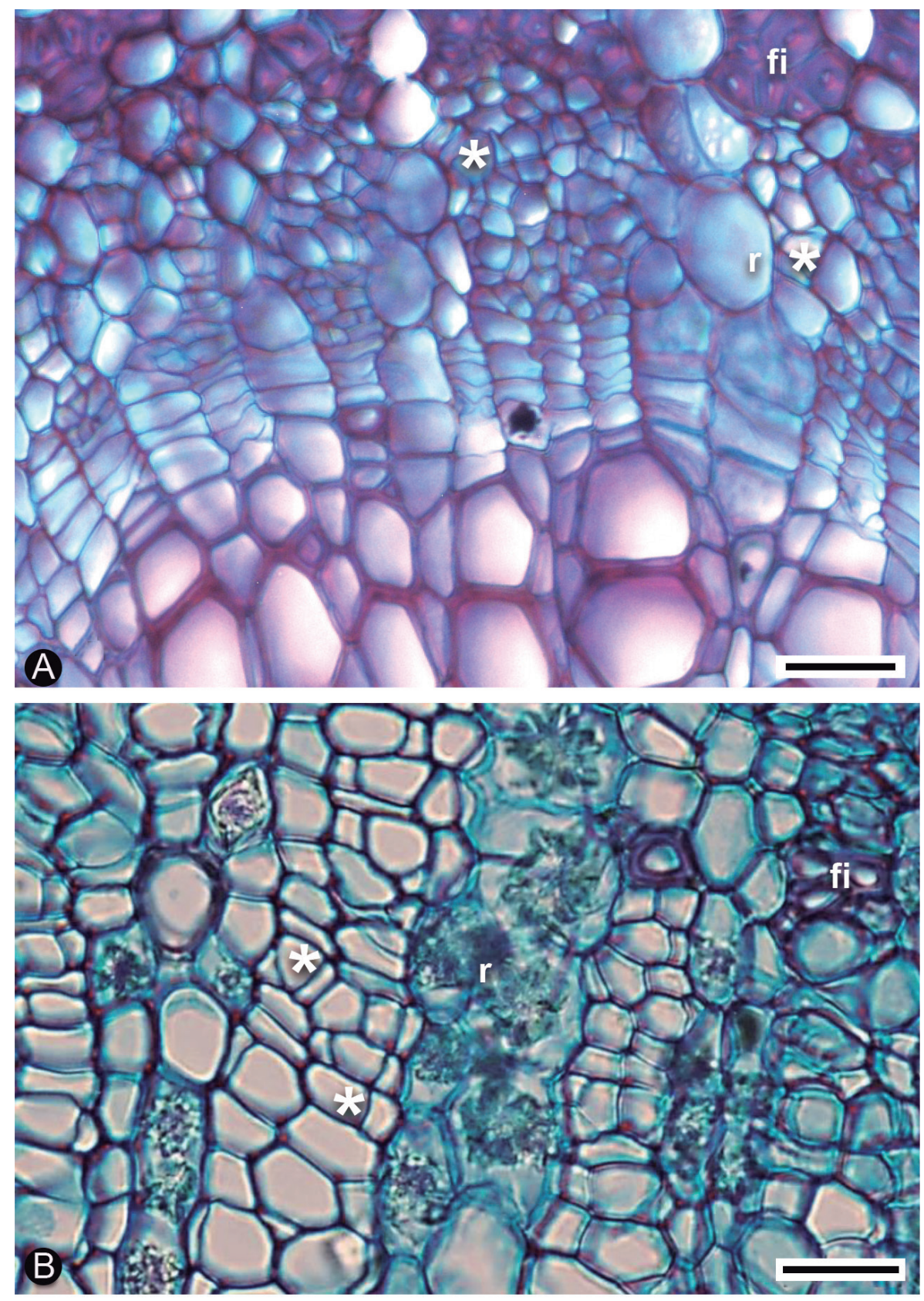

Figura 4: Floema conductor en ramas de $5 \mathrm{~mm}$ de diámetro de Ceiba Mill., CTR. A. Ceiba aesculifolia (Kunth) Britten \& Baker f., elementos del tubo criboso y células acompañantes y abundantes fibras; B. Ceiba pentandra (L.) Gaertn., elementos de tubos y células acompañantes, fibras escasas y radios con drusas. Escala $=25 \mu \mathrm{m}$ en $\mathrm{A}, \mathrm{B}$. CTR=corte transversal, asteriscos $\left({ }^{*}\right)=$ elementos de tubo criboso, $\mathrm{fi}=$ fibras, $\mathrm{r}=$ radio.

En C. pentandra se distingue aún la epidermis con cutícula (Fig. 5B), que se alterna con parches de peridermis alrededor del eje (Figs. 5C, D). En el córtex (SR), C. pentandra presenta una banda de esclerénquima que inicia su proceso de lignificación (Fig. 5C); mientras que en C. aesculifolia esta banda de esclerénquima que se ha formado más tempranamente, rodea algunos canales de mucílago. Se distin- gue el floema no conductor con mayor cantidad de fibras arregladas en bandas tangenciales en ambas especies; en C. aesculifolia existen células lignificadas en los extremos laterales de los radios floemáticos (Fig. 5A, asteriscos) y en C. pentandra estos no se aprecian (Fig. 5C). En C. pentandra los radios toman un curso ondulado y los ETcc comienzan a obliterarse (Fig. 5A). 

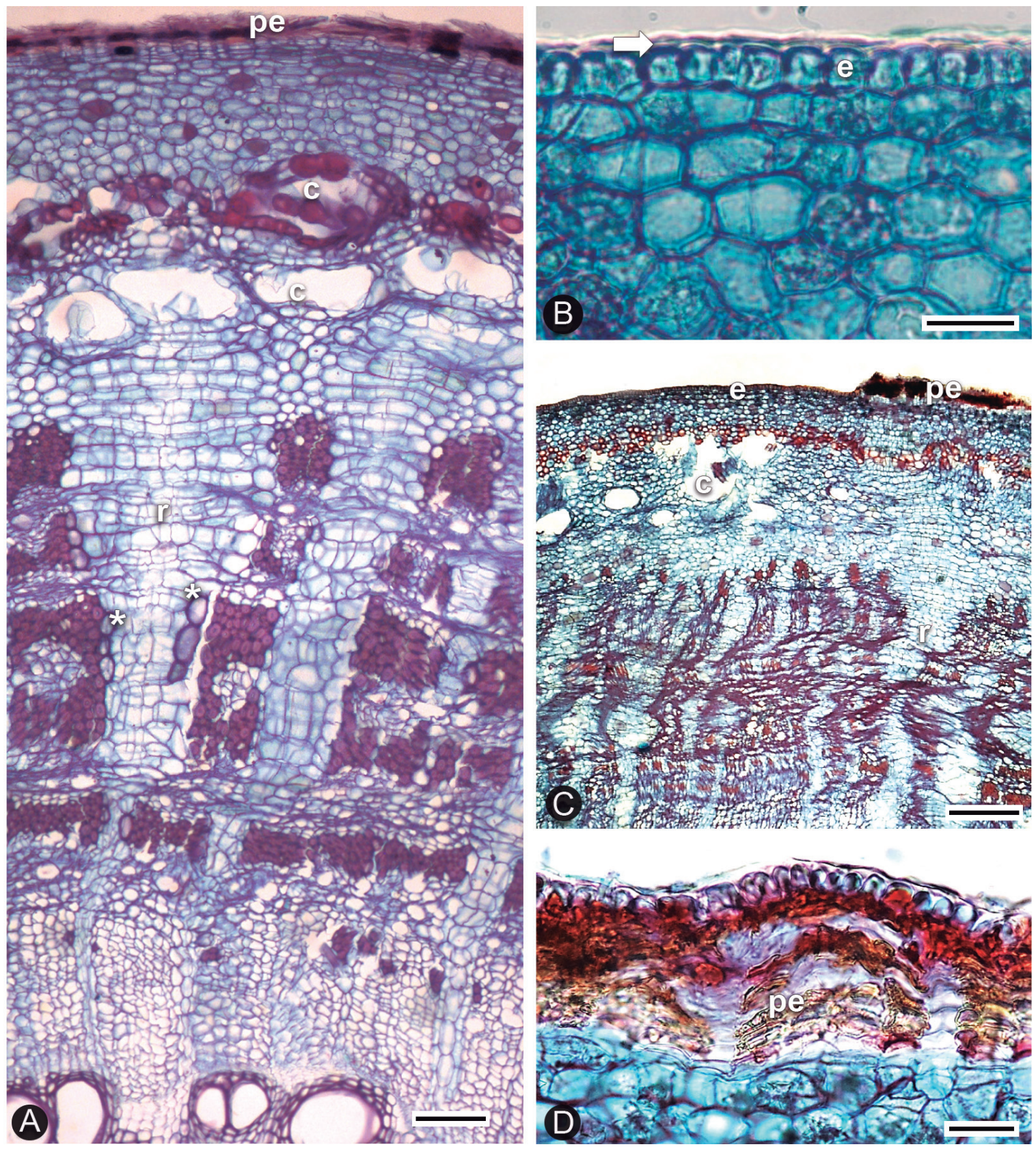

Figura 5: Ramas de $1 \mathrm{~cm}$ de diámetro de Ceiba Mill., CTR. A. Ceiba aesculifolia (Kunth) Britten \& Baker f., peridermis continua y células lignificadas en radios del floema no conductor; B-D. Ceiba pentandra (L.) Gaertn. B. cutícula y epidermis; C. parche de peridermis; D. detalle peridermis. Escala=100 $\mu \mathrm{m}$ en $\mathrm{A} ; 25 \mu \mathrm{m}$ en $\mathrm{B}, \mathrm{D} ; 250 \mu \mathrm{m}$ en $\mathrm{C}$. CTR=corte transversal, $\left({ }^{*}\right)=$ células lignificadas en radios, $\mathrm{C}=$ canal, flecha=cutícula, $\mathrm{e}=$ epidermis, pe=peridermis, $r=$ radio.

Ramas de $2-3 \mathrm{~cm}$ de diámetro

Peridermis sin cambios. Continúan distinguiéndose las tres regiones del córtex (Figs. 6A, B), pero a los $3 \mathrm{~cm}$ en algunas zonas de $C$. pentandra el córtex ya no se aprecia debido a la formación de peridermis sucesivas; por ello los radios dilatados llegan hasta la peridermis (Fig. 6C).
En C. aesculifolia los radios se arreglan en forma de cuñas algo rectas (Fig. 6A); mientras que en $C$. pentandra, estas tienen un curso ondulado (Fig. 6B). En algunos de los radios dilatados se desarrollan grupos de esclereidas (Fig. 6C); en contraste, en C. aesculifolia aún no se forman (Fig. 6A). 

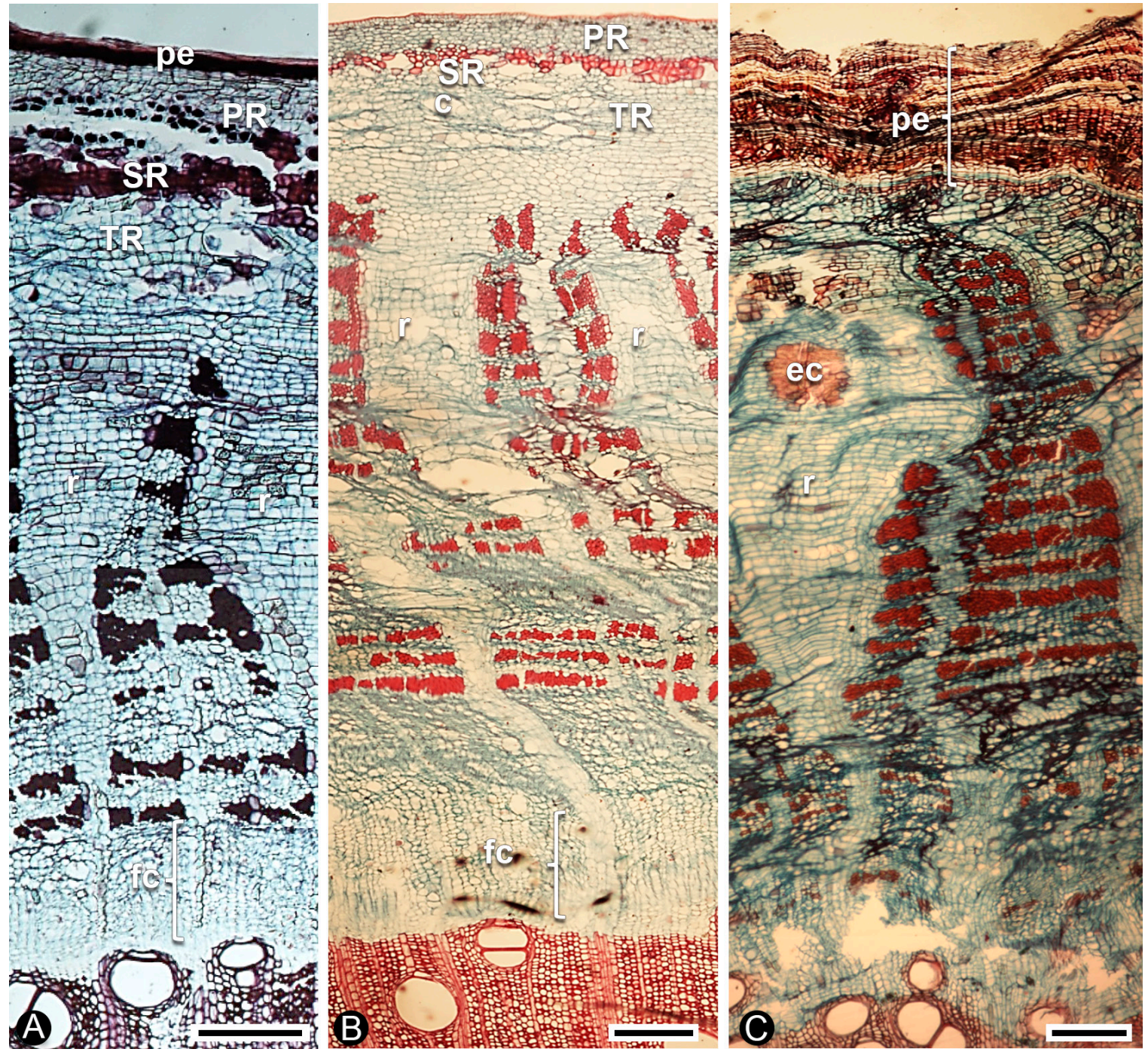

Figura 6: Ramas de 2-3 cm de diámetro de Ceiba Mill., CTR. A. Ceiba aesculifolia (Kunth) Britten \& Baker f., rama $2 \mathrm{~cm}$ de diámetro con peridermis; B. Ceiba aesculifolia (Kunth) Britten \& Baker f., rama $2 \mathrm{~cm}$ de diámetro con epidermis; C. Ceiba pentandra (L.) Gaertn., rama $3 \mathrm{~cm}$ de diámetro con abundante felema y radios dilatados. Escala $=250 \mu \mathrm{m}$ en $\mathrm{A}-\mathrm{C}$. CTR=corte transversal, $\mathrm{c}=\mathrm{canal}$, ec=esclereidas, $\mathrm{fc}=\mathrm{floema}$ conductor, $\mathrm{pe}=\mathrm{peridermis,}$ $\mathrm{PR}=$ primera región, $\mathrm{r}=$ radio, $\mathrm{SR}=$ segunda región, $\mathrm{TR}=$ tercera región.

\section{Ramas (>3- $\leq 9 \mathrm{~cm})$}

En C. aesculifolia no hay cambios en la peridermis ni en el córtex, pero existe mayor desarrollo de esclerénquima, tanto en la periferia del floema (grupos de esclerénquima forman una banda casi continua) como en los radios dilatados del floema no conductor.

En C. pentandra los radios dilatados llegan hasta la peridermis en las zonas que pueden corresponder a las grietas o cicatrices de color pajizo (que se forman externamente en la corteza), pero en algunas zonas los radios se alternan con áreas de parénquima que parecen corresponder a la zona del córtex.
Tronco (>9-15 cm de diámetro)

A los $9 \mathrm{~cm}$ de diámetro, en $C$. aesculifolia la peridermis rodea completamente al eje (Fig. 7A); subyacen restos de la zona cortical, con pocos canales de mucílago o células lignificadas. En el floema no conductor se observan 13-14 bandas tangenciales de fibras y los radios dilatados ya están lignificados a partir de la mitad de sus extremos distales (Fig. 7A).

En C. pentandra $(15 \mathrm{~cm})$ se siguen observando zonas donde no se desarrolla peridermis; en estos casos, la zona por debajo de la epidermis mantiene las tres regiones del córtex (Fig. 7B), con cloroplastos en la PR; no se reconocen 

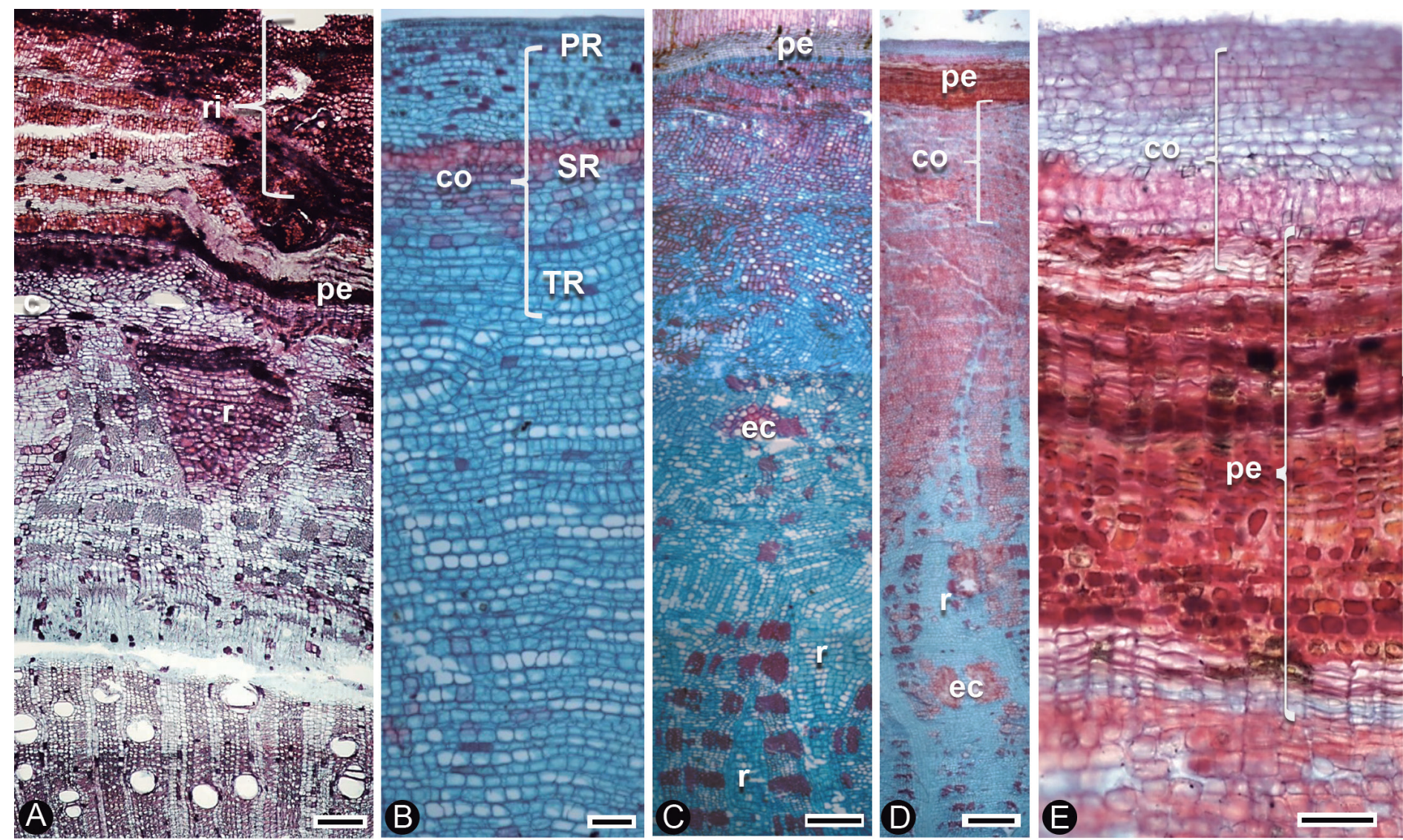

Figura 7: Troncos de Ceiba Mill., CTR. A. Ceiba aesculifolia (Kunth) Britten \& Baker f., de 9-15 cm diámetro, ritidoma y radios con células lignificadas; B. Ceiba pentandra (L.) Gaertn., de 9-15 cm diámetro, regiones del córtex en zonas donde se conserva la epidermis; C. Ceiba aesculifolia (Kunth) Britten \& Baker f., de >80 cm diámetro, por debajo de los aguijones se conserva córtex y una pobre lignificación de los radios; D. Ceiba pentandra (L.) Gaertn., de $80 \mathrm{~cm}$ diámetro, lignificación de córtex y floema no conductor; E. Ceiba pentandra (L.) Gaertn., de $80 \mathrm{~cm}$ diámetro, detalle de peridermis interna y restos del córtex externo exfoliado. Escala $=250 \mu \mathrm{m}$ en A-D; $100 \mu \mathrm{m}$ en $\mathrm{E}$. CTR=corte transversal, $\mathrm{c}=$ canal, $c 0=$ córtex, ec=esclereidas, pe=peridermis, $\mathrm{PR}=$ primera región, $\mathrm{r}=$ radio, ri=ritidoma, $\mathrm{SR}=$ segunda región, $\mathrm{TR}=$ tercera región.

canales por la dilatación del parénquima. En el floema no conductor se presentan 24-25 hileras de bandas tangenciales de fibras y los radios dilatados con escasos grupos de esclereidas.

\section{Tronco ( $\geq 80 \mathrm{~cm}$ de diámetro)}

En ambas especies hay zonas donde se observa la peridermis más interna, delgada, formada por 3-7 estratos de felodermis y 10-15 estratos de felema; este presenta células fuertemente comprimidas y las paredes engrosadas, sobre todo en la periclinal externa. En C. pentandra, el felema de algunas zonas de la peridermis más interna está mejor desarrollado y se observa centrífugamente parte del córtex que exfolia (Fig. 7E). En C. aesculifolia, el córtex se mantiene alrededor del eje en aquellos sitios donde se encuentran los aguijones, con algunas de sus células lignificadas, abundantes drusas (50-60/ $\mathrm{mm}^{2}$ ) y cristales prismáticos (10-15/ $\mathrm{mm}^{2}$ ). En C. pentandra, el córtex también se puede conservar o no, dependiendo de la zona, tal como se ha descrito para diámetros menores; cuando este se mantiene por debajo de la epidermis, todavía se observan células no lignificadas con cloroplastos. En contraste, en las regiones bajo la peridermis la mayoría de las células se encuentran lignificadas (Fig. 7D), con taninos y pocas drusas (15-20/mm²). Los canales de mucílago en el córtex de ambas especies no se distinguen. El floema no conductor en C. aesculifolia tiene los radios con un curso sinuoso y encuentran su límite superior en la región cortical, donde se aprecian varios grupos de esclereidas, cristales prismáticos y drusas, así como taninos. En C. pentandra también abundan bandas tangen- 
ciales de fibras; las más externas colapsan por la dilatación de los radios que también siguen un curso sinuoso y se pierden con la esclerificación (Fig. 7C).

\section{Origen y estructura del aguijón}

En ramas con $3 \mathrm{~mm}$ de diámetro de $C$. aesculifolia, se observa una pequeña protuberancia de células de origen cortical subyacente a las células epidérmicas. Las células que conforman esta protuberancia se dividen anticlinal y periclinalmente (Figs. 8A, B), diferenciándose posteriormente en el aguijón. Las células alineadas radialmente son de pared delgada, rectangulares y - algunas de ellas - contienen una sustancia no identificada de color pardo; las más internas corresponden al felógeno. En la SR del córtex se distingue colénquima (Fig. 8B). En la TR los canales de mucílago son abundantes (Figs. 8A, B); mientras que en las zonas donde no se forman los aguijones, se organizan en hilera.

En individuos de C. aesculifolia con diámetros de 80 cm se observa una clara estratificación en los aguijones. Hay estratos de células del felema con paredes delgadas no suberizadas y lumen radial reducido, que se alternan con células de paredes suberizadas alargadas radialmente (Fig. $8 \mathrm{C})$; los estratos más externos se observan con contenidos de color pardo. En contraste, en $C$. pentandra el aguijón presenta un solo tipo celular. Únicamente hay estratos de células suberificadas, alargadas radialmente y algunas con contenidos obscuros (Fig. 8D).

\section{Discusión}

Los estudios anatómicos sobre desarrollo de cortezas son escasos; la complejidad en su estudio deja ver la poca información que se registra para México y otros países. Debido a ello, este tipo de trabajos se han aplicado en muy pocos taxa (Orduño-Cruz y Terrazas, 1998; Aguilar-Rodríguez et al., 2019) y para Ceiba no se registran. En este estudio se pudo demostrar que existen diferencias evidentes entre especies cercanas como $C$. aesculifolia y $C$. pentandra; algunas de las cuales se relacionan con la estructura de los tejidos de protección (epidermis/peridermis y aguijones) y con la abundancia de cristales. Otras características muestran semejanzas propias de las Malvaceae.
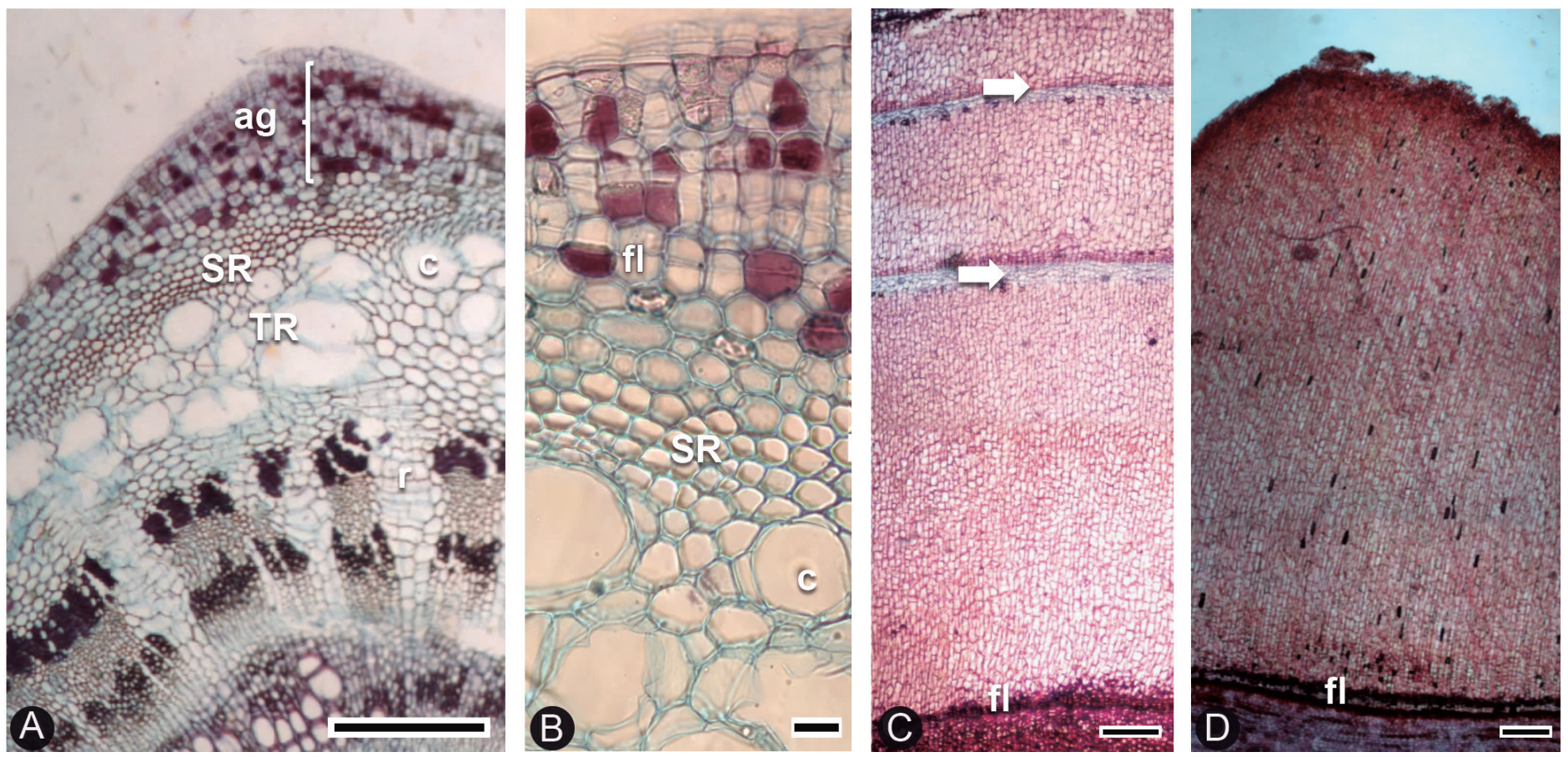

Figura 8: Origen y estructura del aguijón en Ceiba Mill., CTR. A-C. Ceiba aesculifolia (Kunth) Britten \& Baker f. A. aguijón en formación; B. detalle de la diferenciación del felógeno, células de felema y la SR del córtex; C. aguijón estratificado (diámetro $>80 \mathrm{~cm}$ ) con bandas tangenciales de células no suberificadas (flechas); D. Ceiba pentandra (L.) Gaertn., aguijón homogéneo (diámetro $80 \mathrm{~cm}$ ). Escala=250 $\mu \mathrm{m}$ en A, C, D; $25 \mu \mathrm{m}$ en B. CTR=corte transversal, ag=aguijón, $\mathrm{c}=\mathrm{canal}$, fl=felógeno, $\mathrm{r}=$ radio, $\mathrm{SR}=$ segunda región, TR=tercera región. 


\section{Modificaciones en el desarrollo}

Tejidos superficiales

En las ramas de $5 \mathrm{~mm}$ de diámetro de ambas especies se aprecia una epidermis simple. En C. aesculifolia se registra también una hipodermis. Esta se ha reportado también en tallos jóvenes de otras Malvaceae como Chorisia Kunth y Pseudobombax Dugand (Roth, 1981) y en algunas fabáceas y rubiáceas como Hoffmannseggia microphylla Torr. (= Caesalpinia virgata Fisher; Gibson, 1983) y Fadogia agrestis Schweinf. ex Hiern (Raman et al., 2018), respectivamente. La presencia de hipodermis es frecuente en linajes que se desarrollan en climas subhúmedos a semiáridos (Gibson, 1983). Su presencia está relacionada con la disminución de la transpiración (Roth y Delgado, 1968), así como con el almacenamiento de agua (Fahn y Cutler, 1992). La peridermis se establece a partir de un estrato de felógeno por debajo de la hipodermis en $C$. aesculifolia y por debajo de la epidermis en $C$. pentandra. Este desarrollo subepidérmico de la peridermis es común para otras especies (Roth, 1981); generalmente comienza a desarrollarse cerca del ápice de las ramas de plantas leñosas - tanto en gimnospermas como en angiospermas de climas estacionales-, tal como se ha demostrado en Pinus spp., Pithecellobium dulce (Roxb.) Benth., Vachellia farnesiana (L.) Wight \& Arn. (=Acacia cochliacantha Humb. \& Bonpl. ex Willd.) y V. farnesiana (L.) Wight \& Arn. (=A. farnesiana (L.) Willd. (LevYadun y Liphschitz, 1989; Orduño-Cruz y Terrazas, 1998). De acuerdo con Orduño-Cruz y Terrazas (1998), en plantas de clima tropical subhúmedo - donde la estación húmeda es corta-, las ramas que se forman durante ese lapso deben completar la suberificación rápidamente; lo que permitiría soportar altas temperaturas e intensidades luminosas en la temporada seca. Asimismo, como una característica xerofítica en algunas Verbenaceae (Aloysia gratissima (Gillies \& Hook.) Tronc., Lippia turbinata Griseb. y L. integrifolia (Griseb.) Hieron.) también se ha registrado un desarrollo temprano de la peridermis en los tallos (Bonzani et al., 2003) En el mismo tenor, Lev-Yadun y Liphschitz (1989) relacionan la rápida suberificación en la época invernal de las ramas de Pinus, con la protección a la congelación y falta de agua.

Una vez que se ha formado la primera peridermis en las especies estudiadas, los siguientes estratos se ori- ginan sucesivamente en capas más profundas por debajo de la primera. Sin embargo, en $C$. pentandra la formación de peridermis no se lleva a cabo de manera homogénea en el tallo, dado que se observan parches de peridermis y epidermis alternados alrededor del eje (Fig. 5C). Este anillo interrumpido de peridermis está relacionado con la morfología de la corteza, donde las tonalidades verdosas corresponden al tejido epidérmico y las bandas verticales cortas de color pajizo son zonas de peridermis (Fig. 1B, flecha); solo en algunas pequeñas regiones hay ritidoma. En contraste, cuando surge la peridermis (desde el ápice) en $C$. aesculifolia, forma un anillo continuo y las bandas verticales amplias de color amarillo que se observan en el tronco corresponden a una acumulación de peridermis sucesivas, formando un ritidoma angosto (Figs. 1A, 8A).

\section{Córtex}

Desde la rama más joven, el córtex se conforma por tres regiones. De estas, la SR desarrolla células de colénquima que madurarán conforme el eje aumenta su diámetro y hasta formar una banda de esclerénquima, en donde finalmente se diferencian esclereidas. Esta característica se observa más tempranamente en $C$. aesculifolia que en $C$. pentandra. La banda de esclerénquima también se reporta para la misma zona en el tronco de Adansonia digitata (Malvaceae; Kotina et al., 2017), pero no se hace alusión a ella en ejes más jóvenes de esta especie. En C. pentandra es interesante observar que los cloroplastos se conservan tanto en ramas como en tallos maduros. Los cristales y cloroplastos posiblemente ayudan a transmitir la luz y translocar fotonsintatos respectivamente (Gibson, 1983).

En la tercera región (TR) se observan canales de mucílago en ambas especies; su forma está bien definida en ramas jóvenes, pero conforme el eje aumenta en grosor dichos canales se colapsan, hasta que son eliminados por la formación de peridermis sucesivas en los troncos de mayor diámetro. Judd y Manchester (1997) reconocen a los canales y/o cavidades de mucílago en tejidos parenquimatosos, como un carácter sinapomórfico que apoya la monofilia de Malvales. Sin embargo, para Ceiba, Judd y Manchester (1997) no registran dicho atributo; probablemente porque los canales se pierden en la corteza de troncos con grandes diámetros, como se ha explicado anteriormente. Pra- 
do y Demarco (2018) consideran que más allá de su hábito de crecimiento, la capacidad de una planta para producir sustancias secretoras está relacionada con un rasgo filogenético conservado, o a una innovación evolutiva clave que surgió en un grupo particular, influenciado directa o indirectamente por el entorno en el que la planta vive.

Los canales/cavidades en las dos especies de Ceiba se originan de manera esquizógena, dado que se distinguen claramente células epiteliales que rodean a los canales; no obstante, estas son más evidentes en $C$. aesculifolia que en C. pentandra, en la cual no siempre se distinguen. Sin embargo, la forma en que se originan estos canales/cavidades en Malvaceae al parecer no es un carácter universal, ya que Kotina et al. (2017) describen los canales de Adansonia digitata como lisígenos. Una mayor exploración de este aspecto podría ayudar en el futuro a esclarecer linajes en la familia. Por otro lado, es probable que el mucílago que se produce en dichos canales esté relacionado con el hábitat antes descrito, ya que debido a él se facilita el almacenamiento de agua, reducción de la transpiración, protección contra la radiación intensa por dispersión de luz o contra la herbivoría (Gregory y Baas, 1989).

Con respecto a la presencia de canales de mucílago desde las ramas más jóvenes en ambas especies de Ceiba, parece estar relacionada con la protección para el desarrollo de las ramas desde sus primeros estadios; esto es, a partir de los brotes. La presencia de poliaminas en el mucílago de los canales en los estados tempranos de la morfogénesis de los tallos, en especies de climas con invierno frío como Tilia cordata Mill., puede estar relacionado con una tolerancia a la desecación por congelación (Appendino, 2010).

Caracteres que se comparten con la familia Malvaceae

Las características anatómicas del floema que comparten las dos ceibas estudiadas con especies arbóreas tropicales de Bombacoideae (sensu APG IV, 2016), son los radios en forma de embudo, grupos de esclereidas en radios y bandas tangenciales de fibras (Roth, 1981). Además, estas bandas tangenciales de fibras también se han descrito para Malvaviscus arboreus Cav. (Ramírez-Ferreiro, 2015) y Adansonia digitata (Kotina et al., 2017). Con base en los tres caracteres mencionados, Roth (1981) define a las mal- váceas como un grupo homogéneo. En diversos estudios (Roth, 1981; Iqbal y Ghouse, 1982; Malan y van Wyk, 1993; Iqbal, 1995), se explica que las nuevas fibras se originan a partir de células de parénquima que se dividen y crecen intrusivamente para contribuir al ensanchamiento de la banda de esclerénquima; la variación en el arreglo y la distribución de las fibras en el floema secundario permiten distinguir anatómicamente a las especies. Conforme el eje crece en diámetro, los radios van tomando una forma de embudo y estos se alternan con los que no se dilatan, originando un patrón en zig-zag, tal como lo indican Metcalfe y Chalk (1950) y Esau (1969) para C. pentandra. Los grupos de esclereidas en los radios dilatados se encuentran presentes en ambas especies de Ceiba a partir de ramas con ca. $2 \mathrm{~cm}$ de diámetro. La presencia de contenidos como cristales prismáticos, drusas, taninos y los grupos de esclereidas, también pueden considerarse compartidos con otras especies de Malvaceae, como Adansonia digitata (Kotina et al., 2017).

\section{Aguijones}

En la literatura, ha existido controversia sobre el término correcto que deben tener las estructuras punzantes que ornamentan la corteza de Ceiba (Carranza-González y BlancoGarcía, 2000; Gibbs y Semir, 2003; Pagaza-Calderón y Fernández-Nava, 2004) u otras Malváceas como Bombax ceiba L. (Schweingruber y Börner, 2018). De acuerdo con Angyalossy et al. (2016), el aguijón es un ornamento superficial, endurecido, puntiagudo, sin tejido vascular, que se diferencia de las espinas porque estas se encuentran lignificadas y tienen tejido vascular; por tal motivo una espina no puede separarse del órgano que las lleva sin desgarrar el tejido subyacente. Con base en lo anterior, el término correcto para nombrar estas proyecciones de la corteza en Ceiba es aguijón o acúleo -como sinónimos-, y no espina, dado que carecen de tejido vascular. Los resultados aquí obtenidos confirman que estos elementos cónicos se originan a partir de un felógeno (Angyalossy et al., 2016).

Las características anatómicas de los aguijones muestran una marcada diferencia entre $C$. aesculifolia y $C$. pentandra. En la primera, el aguijón es estratificado, con dos tipos celulares que se alternan en el felema; probablemente es un carácter convergente, ya que también se han 
registrado en tres géneros de la familia Rutaceae (Roth, 1981). En especies de Chorisia (Malvaceae) y Hura crepitans L. (Euphorbiaceae) los aguijones son celularmente homogéneos, como en $C$. pentandra. Tanto las espinas como los aguijones han funcionado como una defensa efectiva contra los animales herbívoros que trepan hacia el follaje, las flores o los frutos (Cooper y Ginnett, 1998).

\section{Inclusiones minerales}

Las drusas están presentes en los ápices de C. pentandra y $C$. aesculifolia. Sin embargo, existen diferencias en su número, tanto a lo largo del eje de los individuos como entre las especies. Por ejemplo, estas inclusiones minerales son más abundantes en el ápice de C. pentandra que en C. aesculifolia; pero en el tronco principal esta última especie tiene mayor número de drusas (hasta $50-60 / \mathrm{mm}^{2}$ ) que $C$. pentandra (con 15-20 drusas $/ \mathrm{mm}^{2}$ ). Muñoz-Cázares et al. (2018) registraron resultados similares en la corteza de tallos maduros en ambas especies y también mencionan que en $C$. pentandra las drusas son más escasas que en $C$. aesculifolia.

Los cristales prismáticos en los troncos principales también se presentan en menor número en $C$. pentandra $\left(1-5 / \mathrm{mm}^{2}\right)$ que en C. aesculifolia $\left(10-15 / \mathrm{mm}^{2}\right)$. Al respecto, Muñoz-Cázares et al. (2018) reconocen que los cristales prismáticos son más numerosos que las drusas en $C$. pentandra, pero no se proporcionan datos cuantitativos. Angyalossy et al. (2016) mencionan que los cristales son una característica frecuente en cortezas de especies leñosas y pueden estar presentes en células de parénquima axial y radial o en las células de esclerénquima. Para Tilia cordata (Malvaceae), se reconocen cristales en parénquima cortical (Schweingruber et al., 2019); en algunos representantes de Rosaceae los cristales se observan en células de parénquima axial (Schweingruber et al., 2019). Por su parte, Esau (1969) observó que en algunas especies los cristales se desarrollan frecuentemente en esclereidas y los más comunes son los prismáticos.

En la corteza de ambas especies de Ceiba, las inclusiones más abundantes fueron las drusas; estas se localizan en los radios y son menos frecuentes en el parénquima axial (C. aesculifolia). La variación observada en el número de cristales - en y entre las especies estudiadas - , puede estar relacionada con aspectos físicos, químicos y biológi- cos (Tütüncü et al., 2014). Al respecto, diversos estudios coinciden en que la luz, la temperatura, el pH, la concentración de iones y el proceso de la herbivoría, pueden afectar la ubicación de los cristales en las plantas (Franceschi y Horner, 1980). En lo que se refiere a su función, aún no ha sido bien determinada, pero se ha propuesto que pueden desempeñar un papel en el mantenimiento de los niveles de calcio (Volk et al., 2002), como soporte estructural, o bien como dispersores o concentradores de los rayos luminosos (Horner y Wagner, 1995; Franceschi, 2001); además de actuar como mecanismo de defensa (Molano-Flores, 2001).

\section{Conclusiones}

A pesar de que existen características estructurales de las cortezas de $C$. aesculifolia y $C$. pentandra que comparten con las Bombacoideae (Malvaceae), este estudio reveló diferencias anatómicas de tipo morfológico y que distinguen ambas especies. Algunas diferencias son las siguientes: los parches de peridermis que se alternan con epidermis de C. pentandra, las discrepancias en la cantidad de drusas y cristales prismáticos, los caracteres en las protuberancias apiculadas - típicas de la corteza en Ceiba y que son acumulaciones de felema y carecen de tejido vascular, por lo que se reconocen como aguijones y no como espinas-, y la forma en que se disponen las células, estratificadas en $C$. aesculifolia y homogéneas en $C$. pentandra.

Los cambios estructurales a lo largo del eje, además de las diferencias encontradas entre ambas especies, se reportan por primera vez para el género Ceiba. La formación temprana de la peridermis se interpreta como una adaptación para protección de la insolación y la desecación. El origen de los canales de mucílago difiere entre los representantes de la familia. Un estudio sobre su ontogenia podría arrojar más luz sobre las relaciones taxonómico-evolutivas del grupo. Por ese motivo, este trabajo sienta un precedente para comprender la sistemática de Malvaceae, a través de un análisis anatómico-ontogenético de corteza, y la posible relación de los caracteres estructurales con su adaptación al ambiente.

\section{Contribución de autores}

TT y SAR concibieron y diseñaron el estudio. SGR realizó el trabajo de laboratorio, describió tejidos y escribió el ma- 
nuscrito con la ayuda de SAR y TT. SAR colectó material junto con JDTD y SGR. LYE asesoró en la técnica histológica y revisó cortes. JDTD reconoció especies en campo y realizó la determinación taxonómica. Todos los autores contribuyeron a la interpretación de los resultados, discusión, revisión detallada y la aprobación del escrito final.

\section{Financiamiento}

Este estudio fue financiado por el Programa de Apoyo a los Profesores de Carrera (PAPCA 2016; FESI-DIP-PAPCA-2016-25) y por el Programa de Superación del Personal Académico (PASPA-DGAPA) que asistió a SAR para su estancia sabática en el Instituto de Investigación de Zonas Desérticas (IIZD) de la Universidad Autónoma de San Luis Potosí (9 de agosto de 2016 al 8 de agosto de 2017).

\section{Agradecimientos}

A Dalia Grego-Valencia por su apoyo en parte del trabajo de laboratorio.

\section{Literatura citada}

Aguilar-Rodríguez, S. 1998. Técnicas de laboratorio para el estudio de las embriofitas. In: Plantae. Introducción al estudio de las plantas con embrión. Tejero-Díez, J. D. y M. P. Granillo V. (eds.). Universidad Nacional Autónoma de México, Campus Iztacala. Estado de México, México. Pp. 247-272.

Aguilar-Rodríguez, S., T. Terrazas y X. Camacho-Coronel. 2019. A multiple epidermis or a periderm in Parkinsonia praecox (Fabaceae). Turkish Journal of Botany 43(4): 529-537. DOI: https://doi.org/10.3906/bot-1810-45

Angyalossy, V., M. R. Pace, F. R. Evert, C. R. Marcati, A. A. Oskolski, T. Terrazas, E. Kotina, F. Lens, S. C. MazzoniViveiros, G. Angeles, S. Machado, A. Crivellaro, K. S. Rao, L. Junikka, N. Nikolaeva y P. Baas. 2016. IAWA list of microscopic bark features. International Association of Wood Anatomists Journal 37(4): 517-615. DOI: https://doi. org/10.1163/22941932-20160151

Appendino, G., G. Fontana y F. Pollastro. 2010. 3.08-Natural products drug discovery. In: Mander, L. L. y H.-W. Liu (eds.). Comprehensive Natural Products II. Elsevier. Oxford, UK. pp. 205-236.

APG IV. 2016. An update of the Angiosperm Phylogeny Group classification for the orders and families of flowering plants:
APG IV. Botanical Journal of the Linnean Society 81(1): 1-20. DOI: https://doi.org/10.1111/boj.12385

Biswas, S., K. Gupta y S. N. Talapatra. 2016. A digitized database of bark morphology for identification of common tree species and literature study of bark phytochemicals and therapeutic usage. World Scientific News 42: 143-155.

Bonzani, N. E., E. M. Filippa y G. E. Barboza. 2003. Estudio anatómico comparativo de tallo en algunas especies de Verbenaceae. Anales del Instituto de Biología, Universidad Nacional Autónoma de México, Serie Botánica 74(1): 31-45.

Carranza-González, E. y A. Blanco-García. 2000. Bombacaceae. Flora del Bajío y de Regiones Adyacentes 90: 1-13.

Cooper, M. S. y F. T. Ginnett. 1998. Spines protect plants against browsing by small climbing mammals. Oecologia 113: 219221. DOI: https://doi.org/10.1007/s004420050371

den Outer, R. W. 1972. Tentative determination key to 600 trees, shrubs and climbers from the Ivory Coast, Africa, mainly based on characters of the living bark, besides the rhytidome and the leaf. I. Large Trees. Mededelingen Landbouwhogeschool, Wageningen 72(18): 1-73.

Diego-Pérez, N. y A. Gómez-Campos. 2013. Bombacaceae. Flora de Guerrero 54: 1-33.

Esau, K. 1969. The phloem. Encyclopedia of plant anatomy. Band V, Teil 2. Gebrüder Bornträeger. Berlin-Stuttgart, Germany. $505 \mathrm{pp}$.

Fahn, A. y D. F. Cutler. 1992. Xerophytes. Encyclopedia of plant anatomy. Band XIII, Teil 3. Gebrüder Bornträeger. BerlinStuttgart, Germany. 176 pp.

Franceschi, V. R. 2001. Calcium oxalate in plants. Trends in Plant Science 6(7): 331. DOI: https://doi.org/10.1016/S13601385(01)02014-3

Franceschi, V. R. y H. T. Horner. 1980. Calcium oxalate crystals in plants. The Botanical Review 46: 361-427. DOI: https://doi. org/10.1007/BF02860532

Ghouse, A. K. M., M. Iqbal, F. A. Siddiqui y A. Jamal. 1979. Taxonomic significance of sclerenchyma distribution in the secondary phloem of some Indian tropical trees. Feddes Repertorium 90(3): 173-178. DOI: https://doi.org/10.1002/ fedr.19790900305

Gibbs, P. y J. Semir. 2003. A taxonomic revision of the genus Ceiba Mill. (Bombacaceae). Anales del Jardín Botánico de Madrid 60(2): 259-300. DOI: https://doi.org/10.3989/ajbm.2002. v60.i2.92 
Gibson, A. C. 1983. Anatomy of photosynthetic old stems of nonsculent dicotyledons from North American deserts. Botanical Gazette 144(3): 347-362. DOI: https://doi. org/10.1086/337383

Gregory, M. y P. Baas. 1989. A survey of mucilage cells in vegetative organs of the dicotyledons. Israel Journal of Botany 38(2-3): 125-174.

Hamann, D. T., E. F. Smets y F. Lens. 2011. A comparison of paraffin and resin-based techniques used in bark anatomy. Taxon 60(3): 841-851. DOI: https://doi.org/10.1002/tax.603016

Hawthorne, W. 2006. Characters of whole plants or plant populations. In: Lawrence, A. y W. Hawthorne (eds.). Plant identification: Creating user-friendly field guides for biodiversity management. World Wide Fund for Nature, UNESCO, Royal Botanic Gardens Kew, Earthscan. London, UK. Pp. 138-149.

Horner, T. H. y L. B. Wagner. 1995. Calcium oxalate formation in higher plants. In: Khan, R. S. (ed.). Calcium oxalate in Biological systems. CRC Press, Inc. Boca Raton, USA. Pp. 5372.

Iqbal, M. 1995. The cambial derivates. Encyclopedia of plant anatomy. Gebruder Borntraeger. Berlin-Stuttgart, Germany. $363 \mathrm{pp}$.

Iqbal, M. у A. K. M. Ghouse. 1982. Comparative bark feature of some arid zone species of Acacia and Prosopis. Phytomorphology 32(4): 373-380.

Jiménez-Saa, J. H. 1967. Los árboles más importantes de la región de Upala, Costa Rica: manual de identificación en el campo. Informe No. 3. Proyecto de Desarrollo Forestal Zonas Selectas. San José, Costa Rica. 183 pp.

Johansen, D. A. 1940. Plant microtechnique. McGraw-Hill Book Company. New York, USA. 523 pp.

Judd, W. S. y S. R. Manchester. 1997. Circumscription of Malvaceae (Malvales) as determined by a preliminary cladistic analysis of morphological, anatomical, palynological and chemical characters. Brittonia 49(3): 384-405. DOI: https://doi. org/10.2307/2807839

Kotina, L. E., A. A. Oskolski, P. M. Tilney y B. E. Van Wyk. 2017. Bark anatomy of Adansonia digitata L. (Malvaceae). Adansonia 39(1): 31-40. DOI https://doi.org/10.5252/a2017n1a3

Lev-Yadun, S. y N. Liphschitz. 1989. Sites of first phellogen initiation in conifers. International Association of Wood
Anatomists Bulletin n.s. 10(1): 43-52. DOI. https://doi. org/10.1163/22941932-90001110

Malan, J. W. y A. E. van Wyk. 1993. Bark structure and preferential bark utilisation by the African elephant. International Association of Wood Anatomists Journal 14(2): 173-185. DOI: https://doi.org/10.1163/22941932-90001314

Metcalfe, C. R. 1979. The stem. In: Metcalfe, C. R. y L. Chalk (eds.). Anatomy of the dicotyledons. Vol. 1. Systematic anatomy of the leaf and stem, with a brief history of the subject. Clarendon Press. Oxford, UK. Pp. 166-221.

Metcalfe, C. R. y L. Chalk. 1950. Anatomy of the Dicotyledons. Clarendon Press. Oxford, UK. Pp. 235-242. DOI: https://doi. org/10.1111/j.2042-7158.1950.tb13008.x

Molano-Flores, B. 2001. Herbivory and calcium concentrations affect calcium oxalate crystal formation in leaves of Sida (Malvaceae). Annals of Botany 88(3): 387-391. DOI: https:// doi.org/10.1006/anbo.2001.1492

Muñoz-Cázares, N., S. Aguilar-Rodríguez, R. García-Contreras, M. Soto-Hernández, M. Martínez-Vázquez, M. PalmaTenango, F. J. Padro-Galbarro e I. Castillo-Juárez. 2018. Phytochemical screening and anti-virulence properties of Ceiba pentandra and Ceiba aesculifolia (Malvaceae) bark extracts and fractions. Botanical Sciences 96(3): 415-425. DOI: https://doi.org/10.17129/botsci.1902

Nicolson, D. H. 1979. Nomenclature of Bombax, Ceiba (Bombacaceae) and Cochlospermum (Cochlospermaceae) and their type species. Taxon 28(4): 367- 373. DOI: https:// doi.org/10.2307/1219749

Nikon Corporation. 1991-2006. NIS- Elements, version 2.33. Tokio, Japón.

Orduño-Cruz, A. y T. Terrazas. 1998. Anatomía de la corteza de tres especies de leguminosas. Origen y desarrollo. Boletín de la Sociedad Botánica de México 63: 51-65. DOI: https:// doi.org/10.17129/botsci.1567

Pagaza-Calderón, E. M. y R. Fernández-Nava. 2004. La familia Bombacaceae en la Cuenca del río Balsas, México. Polibotánica 17: 71-102.

Pérez-Jiménez, L. A. y J. Barajas-Morales. 2011. Árboles de selvas secas de México. Identificación mediante cortezas. Publicaciones Especiales 23. Instituto de Biología, Universidad Nacional Autónoma de México. México, D.F., México. 96 pp. 
Prado, E. y D. Demarco. 2018. Laticifers and secretory ducts: similarities and differences. In: Hufnagel, L. (ed.). Ecosystem services and global ecology. IntechOpen. London, UK. Pp. 103-123. DOI: https://doi.org/10.5772/intechopen.75705

Raman, V., J. M. Jane, M. Budel, J. Zhao, J-Y Bae, B. Avula, A. G. Osman, Z. Alia e I. A. Khan 2018. Microscopic characterization and HPTLC of the leaves, stems and roots of Fadogia agrestis - an African folk medicinal plant. Revista Brasileira de Farmacognosia 28(6): 631-639. DOI: https:// doi.org/10.1016/j.bjp.2018.07.006.

Ramírez-Ferreiro, A. A. 2015. Anatomía de madera y corteza de especies de un bosque mesófilo de montaña de Veracruz, México. Tesis de licenciatura. Facultad de Estudios Superiores Iztacala, Universidad Nacional Autónoma de México. Estado de México, México. 92 pp.

Rollet, B. 1980. Intérêt de l'étude des écorces dans la détermination des arbres tropicaux sur pied. Bois et forêst des tropiques 194: 3-28. DOI: https://doi.org/10.19182/ bft1980.194.a19398

Rollet, B. 1982. Intérêt de l'étude des écorces dans la détermination des arbres tropicaux sur pied. Bois et forats des tropiques 195: 31-50.

Roth, I. 1981. Structural patterns of tropical barks. In: Encyclopedia of Plant Anatomy. Berlin, Germany. 609 pp.

Roth, I. y M. Cova O. 1969. Estructura anatómica de la corteza de algunas especies de moráceas venezolanas. Acta Botanica Venezuelica 6: 60-76.

Roth, I. y M. Delgado. 1968. Desarrollo de la epidermis pluriestratificada y de la corteza primaria en el tronco de Parkinsonia aculeata L. Acta Botanica Venezuelica 3(1/4): 265-277.

Roth, I. y A. M. Giménez. 1997. Argentine Chaco forests: Dendrology, tree structure, and economic use, 1. Encyclopedia of plant anatomy-Band XIV(5): The semiarid Chaco. Gebrüder Bornträeger. Berlin-Stuttgart, Germany. 180 pp.
Rzedowski, J. 1978. Vegetación de México. Ed. Limusa. México, D.F. México. 432 pp.

Schweingruber, H. F. y A. Börner. 2018. The plant stem. A microscopic aspect. Springer. Cham, Switzerland. Pp. 43-78. DOI: https://doi.org/10.1007/978-3-319-73524-5_6

Schweingruber, H. F., P. Steiger y A. Börner. 2019. Bark Anatomy of Trees and Shrubs in the Temperate Northern Hemisphere. Springer Nature. Cham, Switzerland. 394 pp. DOI: https:// doi.org/10.1007/978-3-030-14056-4

Thiers, B. 2018. Continuously updated. Index Herbariorum: A global directory of public herbaria and associated staff. New York Botanical Garden's Virtual Herbarium. New York, USA. http://sweetgum.nybg.org/ih/ (consultado octubre, 2020).

Trockenbrodt, M. 1991. Qualitative structural changes during bark development in Quercus robur, Ulmus glabra, Populus tremula and Betula pendula. International Association of Wood Anatomists Bulletin n.s. 12(1): 5-22. DOI: https://doi. org/10.1163/22941932-90001199

Tütüncü, K. S., N. Öztürk y F. Dane. 2014. Occurrence, types and distribution of calcium oxalate crystals in leaves and stems of some species of poisonous plants. Botanical Studies 55(32): 1-9. DOI: https://doi.org/10.1186/1999-3110-55-32

Villaseñor, J. L. 2016. Checklist of the native vascular plants of Mexico. Revista Mexicana de Biodiversidad 87: 559-902. DOI: https://doi.org/10.1016/j.rmb.2016.06.017

Volk, G. M., V. J. Lynch-Holm, T. A. Kostman, L. J. Goss y V. R. Franceschi. 2002. The role of druse and raphide calcium oxalate crystals in tissue calcium regulation in Pistia stratiotes leaves. Plant Biology 4: 34-45. DOI: https://doi. org/10.1055/s-2002-20434

Yunus, M., D. Yunus y M. Iqbal. 1990. Systematic bark morphology of some tropical trees. Botanical Journal of the Linnean Society 103(4): 367-377. DOI: https://doi. org/10.1111/j.1095-8339.1990.tb00196.x 